Brit. J. prev. soc. Med. (1963), 17, 128-132

\title{
SOURCES OF SEASONAL VARIATION IN RECORDED LENGTH
}

\section{OF GESTATION}

\author{
BY \\ R. G. RECORD AND IAN LECK \\ Department of Social Medicine, University of Birmingham
}

An examination of the birth records of New York City for the years 1957-59 reported by Hewitt (1961) indicated that pregnancies which terminated in the summer months tended to be of shorter duration than those which terminated in the winter. February births showed the longest gestations and August births the shortest, the estimated difference being between one and two days. It seemed important to decide whether this fluctuation had a biological origin, or could be ascribed at least in part (as Hewitt suggested) to some seasonal variation either in obstetric practice (such as the use of oxytocic drugs) or in the accuracy with which gestation length was measured. An obvious first step in pursuing this problem was to decide whether the same phenomenon was observable in another area. The present communication reports the results of such an inquiry.

\section{MATERIAL}

Since 1949, comprehensive records of all live births and stillbirths to Birmingham residents have been kept on punched cards by the city's Public Health Department (Charles, 1951). A high proportion of the cards give an estimate, to the nearest week, of the length of gestation. In accordance with the usual practice, this was measured from the date of onset of the last menstrual period given in the antenatal record.

It was considered that three years would provide adequate numbers for the present study, and the period 1952-54 was chosen because the records of these years had already been partly analysed for another investigation.

\section{Method}

The estimates of gestation length in the records used in this inquiry had been made by clerks using obstetric calculators with a circular scale calibrated in weeks (Fig. 1, opposite).
The accuracy of these calculators (which were provided by the manufacturers of a well-known infant food) is impaired by three defects in their design:

(i) The intervals February 25 to March 3 (a 6-day period except in leap years) and December 29 to January 7 (a 9-day period) are each measured as one week. The calculator therefore over-estimates by 1 day pregnancies which include a non-leap year February but not the end of December, and the converse causes an under-estimate of 2 days. Pregnancies which include both these times are under-estimated by 1 day.

(ii) The calculator is calibrated in weeks only up to 40 weeks. The duration of pregnancies extending beyond 40 weeks is therefore liable to be rounded off to this length.

(iii) In some calculators (e.g. that reproduced in Fig. 1), the printing of the inner circular scale is not concentric, so that each of the intervals on this scale from 0 to 20 occupies a little more than a week on the outer scale and the calibrations from about 30 to 40 slightly less than a week. The net result is to under-estimate the length of pregnancy.

The seasonal error due to the first of these defects was removed by applying the corrections shown in the Table, column (b). Except for one month - February - these corrections are not whole numbers because they apply to the 3 years 1952-54 (one of which was a leap year) and because pregnancies are of varying durations. As a result, only a proportion of pregnancies terminating in a certain month included one or both periods when the calculator was at fault.

The non-seasonal error, due to the second and third defects noted above, was estimated by calculating arithmetically the exact duration of gestation of a sample of 3,000 births from various periods and 128 


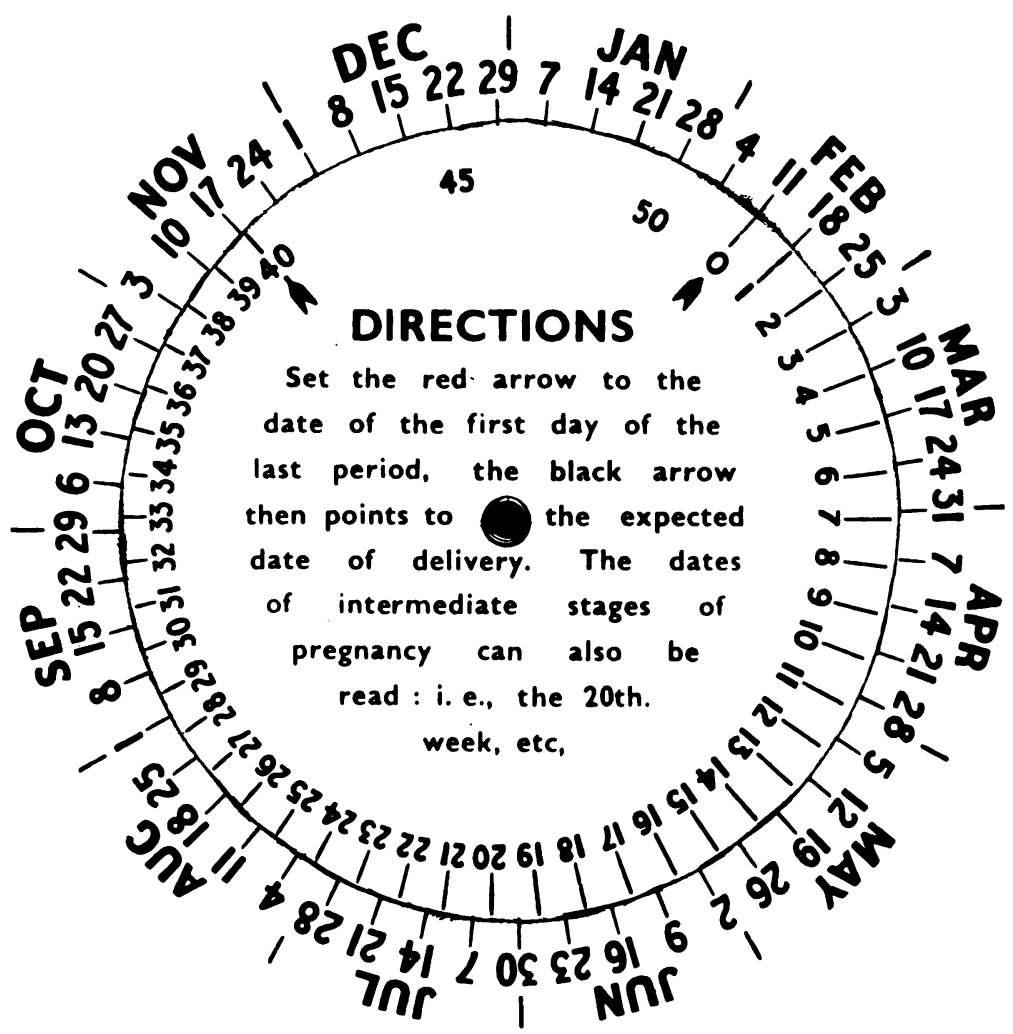

FIG. 1.-Type of obstetric calculator used in Birmingham.

TABLE

MEAN LENGTH OF GESTATION (DAYS) ACCORDING TO MONTH OF BIRTH, SHOWING CORRECTION FOR ERRORS IN CALIBRATION OF OBSTETRIC CALCULATOR

\begin{tabular}{|c|c|c|c|}
\hline $\begin{array}{l}\text { Month of } \\
\text { Birth } \\
(1952-54)\end{array}$ & $\begin{array}{c}\text { Mean Recorded } \\
\text { Gestation Length } \\
(a)\end{array}$ & $\begin{array}{l}\text { Correction for } \\
\text { Seasonal Error } \\
\qquad(b)\end{array}$ & $\begin{array}{c}\text { Corrected Mean } \\
\text { Gestation Length } \\
(a+b+0 \cdot 41 \\
\text { days })^{*}\end{array}$ \\
\hline $\begin{array}{l}\text { January.. } \\
\text { February } \\
\text { March } . . \\
\text { April } \quad . . \\
\text { May } \quad . . \\
\text { June } \quad . . \\
\text { July } \quad . \\
\text { August } \\
\text { September } \\
\text { October.. } \\
\text { November } \\
\text { December }\end{array}$ & $\begin{array}{l}276 \cdot 91 \\
277 \cdot 01 \\
278 \cdot 17 \\
278 \cdot 07 \\
278 \cdot 06 \\
277 \cdot 95 \\
277 \cdot 86 \\
277 \cdot 99 \\
278 \cdot 17 \\
279 \cdot 30 \\
279 \cdot 32 \\
278 \cdot 40\end{array}$ & $\begin{array}{l}+1.87 \\
+2.00 \\
+1.31 \\
+1.33 \\
+1.33 \\
+1.34 \\
+1.31 \\
+1.30 \\
+1.16 \\
+0.05 \\
-0.58 \\
-0.17\end{array}$ & $\begin{array}{l}279 \cdot 19 \\
279 \cdot 42 \\
279 \cdot 89 \\
279 \cdot 81 \\
279 \cdot 80 \\
279 \cdot 70 \\
279 \cdot 58 \\
279 \cdot 70 \\
279 \cdot 74 \\
279 \cdot 76 \\
279 \cdot 15 \\
278 \cdot 64\end{array}$ \\
\hline
\end{tabular}

* 0.41 days is the correction for the non-seasonal error (see text).

comparing the mean with that of their recorded values corrected for the seasonal error. The "true" mean was 0.41 days greater than the recorded mean.

\section{RESULTS}

There were 56,148 births (live and still) during the period; length of gestation was known for 47,285. Of these, 145 resulted from pregnancies of less than 28 weeks' duration and have been excluded because they are unrepresentative. The analysis which follows relates therefore to 47,140 births.

When allowance is made both for the seasonal error and the systematic error of the calculator, the mean length of gestation approaches the conventional value of $\mathbf{2 8 0}$ days for each of the months March to October, but the means are rather lower for births in the winter months, particularly in December (Table).

At first sight this seems to indicate that there is a seasonal variation in length of gestation, but a closer examination shows that this pattern is to a large extent due to a seasonal variation in the number of births. In Birmingham the daily number of births is below average during the last 3 months of the year and is particularly low in November (Fig. 2). Since 
only about four-fifths of births occur in the month expected, most of the remainder being distributed between the preceding month and the following month, the relatively low number of births in November leads to under-representation of births of short duration in October and of births of long duration in December. Thus the mean length of gestation of October births will tend to be high and that of December births low.

Seasonal variations in the number of births can therefore cause differences from one month to another in mean duration of gestation even when there is no real seasonal variation in gestation length. The magnitude of this effect is indicated in Fig. 3, which shows the mean durations of gestation which would occur if the number of births varied as in Fig. 2 and if the distribution of gestation length remained the same throughout the year. The working table used to prepare the figure is too bulky to be reproduced, but the principle can be described briefly. Examination of the distribution of gestation length of a large series of births indicates that about 79 per cent. occur in the month expected and have a mean duration of 282.8 days. 13 per cent. occur 1 month early (mean $257 \cdot 1$ days), 2 per cent. 2 months early (mean $223 \cdot 4$ days), and 6 per cent. 1 month late (303.0 days). The births in a given month, say October, are therefore made up of 2 per cent of infants who, had they gone to term, would have been born in December, 13 per cent. of the births which should have occurred in November, 79 per cent. of October's births, and 6 per cent. of September's births. All births in each month

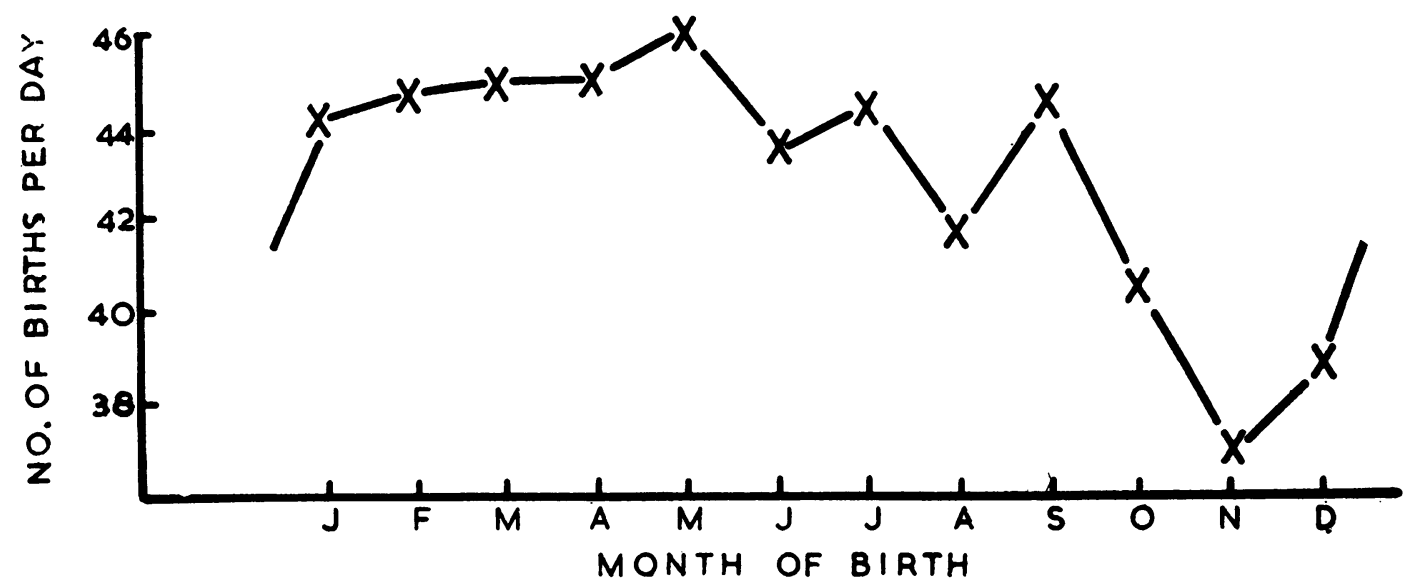

FIG. 2.-Daily number of births according to month (Birmingham, 1952-54).

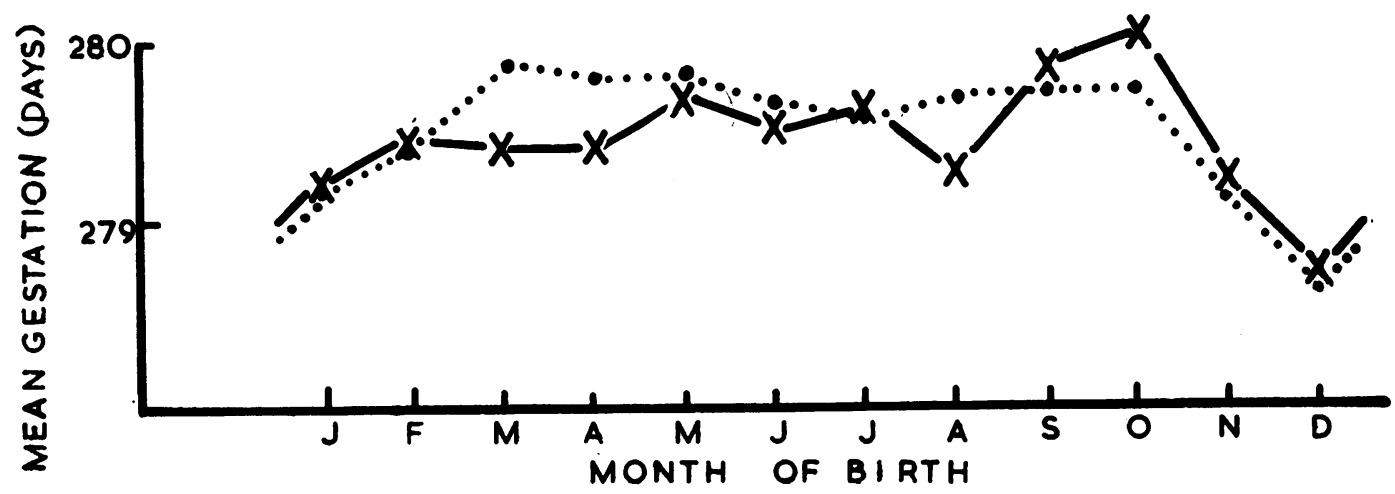

FIG. 3.-Estimated mean gestation (days), showing variation wholly due to seasonal fluctuations in birth rate (continuous line). Corrected observed means as in Table shown by dotted line. 
were re-allocated on this basis and the mean gestations were calculated using the group means indicated above. The results of this procedure, shown as a continuous line in Fig. 3, can be compared with the observed values shown in the Table and reproduced in Fig. 3 as a dotted line.

This comparison suggests that the low mean gestations of November, December and January births can be ascribed wholly to the relatively low birth rate around November. The seasonal variation in length of gestation which cannot be explained in this way (an increase in March, April and August, and a decrease in October) is slight and may be no more than fortuitous. (In this series, the standard error of the mean for each month is about $0 \cdot 3$ days.)

\section{Discussion}

The method used by Hewitt to examine length of gestation in New York avoided the error which might result from seasonal variations in the birth rate. We understand that, although calculators of circular type were used in that survey, they were free from the defects found in those used in Birmingham. We have to inquire, therefore, whether calculators of this type could be subject to other faults which might result in spurious seasonal variations. A few experiments with models soon showed that the circular type of calculator has to be constructed with great care if seasonal errors are to be avoided. Quite a small degree of eccentricity in the mounting of the inner scale can result in marked seasonal variations in the apparent length of gestation.

This is illustrated in Fig. 4, which shows a simplified pattern of calculator, the year being divided into twelve equal parts represented on the scale by the intervals AB, BC, CD, etc. The inner scale is attached at its centre to a point $(X)$ which does not quite coincide with the centre of the outer scale (Y). Assuming that a pregnancy extends over nine intervals, one which starts at $\mathbf{A}$ and terminates at $\mathbf{J}$ would occupy a little more than nine intervals on the inner scale and its duration would therefore be over-estimated. On the

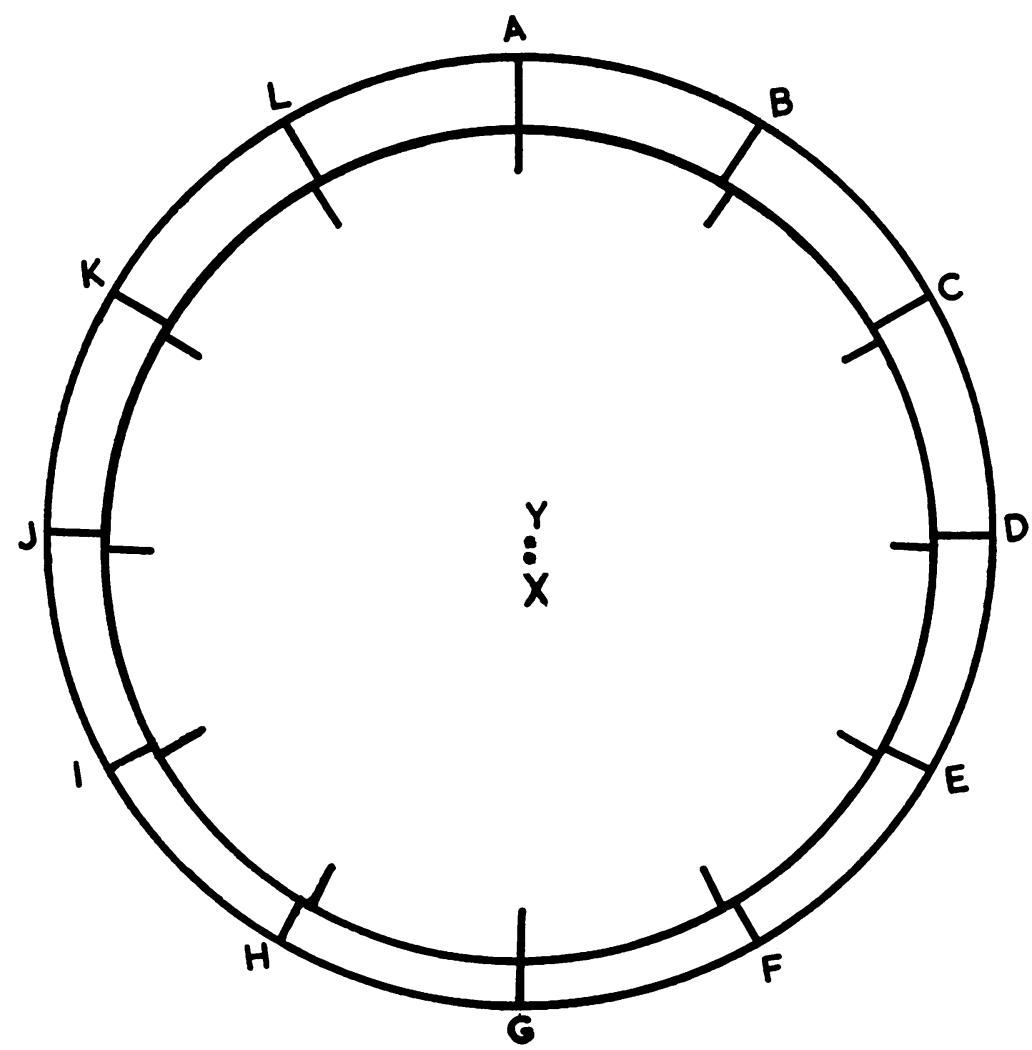

Fig. 4.-Simplified pattern of circular scale calculator, showing effect of eccentric mounting of inner scale. 


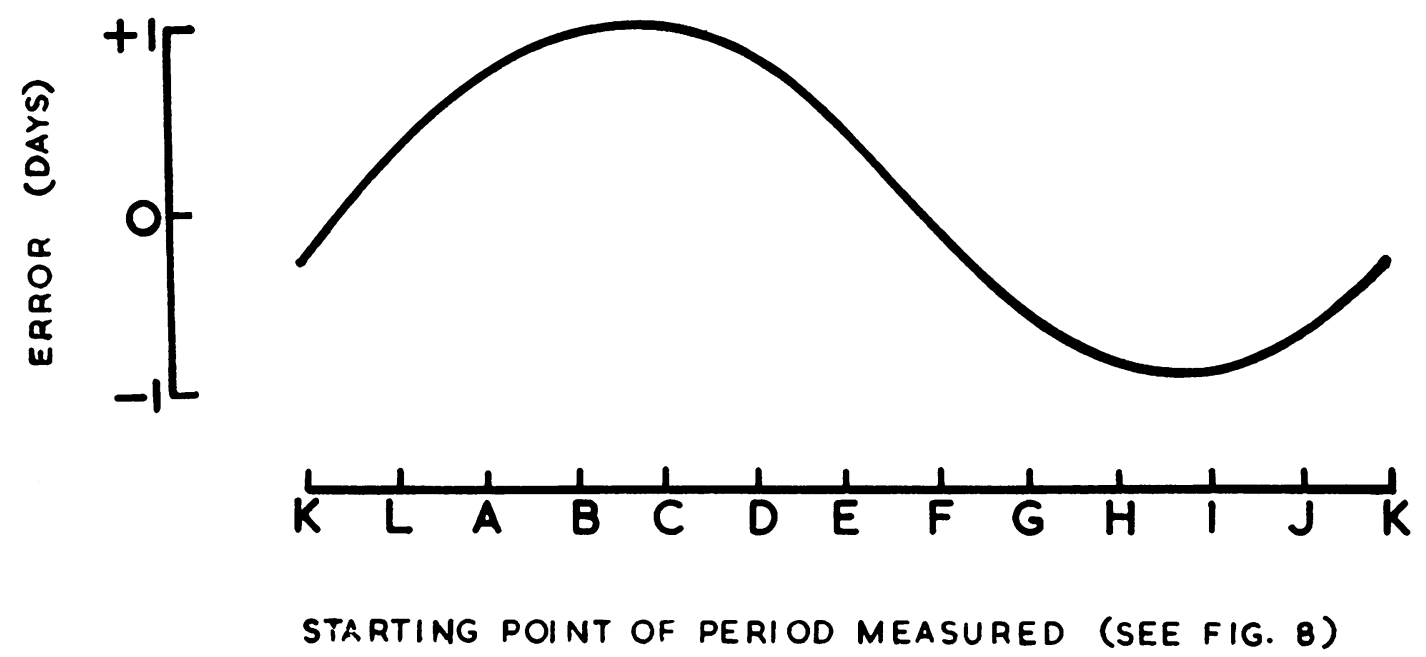

FIG. 5.-Error in measuring 9 months by use of calculator with inner scale mounted eccentrically (shown in Fig. 4), when the distance between the centres of the two circular scales is 0.6 per cent. of the diameter.

other hand, a pregnancy commencing at $G$ and ending at $\mathrm{D}$ would occupy less than nine intervals on the inner scale and its length would be under-estimated. This calculator would over-estimate the duration of all pregnancies starting during the period L A B ....E and would under-estimate all those starting during F G H . . . K. It would be correct only for those starting midway between $E$ and $F$ and between $K$ and L. It can be shown geometrically that the error takes the form of a sine curve and that its magnitude is a function of the distance $X Y$ related to the diameter of the inner scale. The range of the error is 2 days when $X Y$ is 6 thousandths of the diameter (Fig. 5).

We do not know whether the use of calculators with this fault was responsible for the seasonal pattern reported by Hewitt (1961) or whether in New York unlike Birmingham there is a true seasonal variation in length of gestation. But it would seem that, although the circular scale calculator is useful in obstetric practice where an error of 1 or 2 days is usually of little consequence, it should not be used for research purposes unless it is carefully constructed and tested for systematic and seasonal errors.
It is probably wiser to use for this work the slide type of calculator with linear scales.

\section{Summary}

Analysis of 47,140Birmingham birth recordsshowed? no significant seasonal fluctuation in duration of gestation after correcting for faults in the obstetric calculators and after making allowance for the effect of seasonal variation in the birth rate. It is suggested that, if obstetric calculators of circular type are used, they should be carefully examined for systematic and seasonal errors.

We are indebted to Dr E. L. M. Millar and his staff for access to Birmingham birth records, to Dr Duncan W. Clark for information about the type of obstetric calculator used in New York, and to Mrs Eileen Armstrong, Miss Ida Giles, and Mrs Betty Mann, for help in the analysis of our data.

\section{REFERENCES}

Charles, E. (1951). Brit. J. soc. Med., 5, 41.

Hewitt, D. (1961). Amer. J. Obstet. Gynec., 82, 940. 